\title{
Preliminary Study on the Role of Social Presence in Blended Learning Environment in Higher Education
}

\author{
Kamaruzaman Jusoff (Corresponding author) \\ Faculty of Forestry, Universiti Putra Malaysia, Serdang 43400 Selangor, Malaysia \\ Tel: 60-3-8946-7176_E-mail:kjusoff@yahoo.com \\ Rouhollah Khodabandelou \\ Faculty of Humanistic, Arak University, 38138-5-3945, Arak, Iran \\ Tel: 98-25-1886-3444Ｅ-mail: khodaband@gmail.com
}

\begin{abstract}
This paper contributes to the growing body of knowledge which identifies benefits for Blended Learning in the understanding of social processes role. It reports on an exploratory study into the role of social presence in blended learning environment. Employing a qualitative methodology, the study sought to understand social presence of learners in Blended Learning environment. The paper presents the definition of social presence as described by blended learning instructors and it's role in the development of Blended Learning environment.
\end{abstract}

Keywords: Social presence, Blended learning, Higher education, Qualitative research

\section{Introduction}

Today, we are in the age of information and distance education in this age has taken a new paradigm for teaching and learning. Universities, colleges and other academic institutions are offering a variety of distance education courses and programs to meet the needs of students. For example, in United States over 3 million online learners are now pursuing Web-based courses (Allen \& Seaman, 2006).

One of the many platforms of Web-based courses is Blended Learning. It is a form of distance education based on Internet technology, which combines face-to-face instruction with on-line instructional resources and is emerging as a major global trend (Driscoll, 2002). Today Blended Learning is a new method among many higher education institutions and also it is becoming more prevalent in higher education. Web-based instruction in general and blended learning environments especially, have impacted in the areas of everyone life style and it has the potential to reinforce the core of teaching and learning (Gómez \& Igado, 2008) as well as provides the learner with higher levels of learning.

According to social constructivist theory, learning occurs in a context of social interactions through reflection, collaboration, and articulation (Yildiz, 2009). In social constructivist learning environments, the role of the teacher becomes facilitator. One of the advantages of blended courses that are based on social constructivist theory is the increase in collaborative activities and interaction between student and student through tasks, and activities in and out of class (Tan et al., 2005).

A review of literature in the area of online and blended learning has confirmed that, there are so many factors that influence student's learning and play an important role in their teaching and learning process. One of them is how students feel socially in an online community (Caplas, 2006). This feeling is known as Social Presence which plays an important role in students' successful learning. Marcus (2006) emphasizes that social presence is necessary to improve effective instruction in traditional and technology-based environments. Social Presence concept is the key of success or failure of any new innovation or change in teaching and learning environments. Understanding teachers' perception of Social Presence in Blended Learning is a fundamental step that may provide insights into enhancing students' learning.

A number of studies that examined socially oriented factors in Internet-based learning have indicated that learners' feelings are much more important in this environment than in traditional environment (Gunawardena \& Zittle, 1997; \& Picciano, 2002). For example, Picciano (2002) argued that it is possible for students to interact with each other without ever having a sense of belonging to the class or a group of students. Social presence is about relationships and how students and instructors connect to each other in the virtual world to interact socially, question each other, share knowledge and engage in activities that are mediated through the use of technology (Tu, 2002a). Social presence needs to be further researched because of its role in improving student's performance in blended learning environment is unknown. Garrison \& Kanuka (2004) stated that it is important to examine social presence in blended learning college courses in order to aid course designers to design and develop online classes for enhance of students learning. 
Due to the lack of research on social presence in blended learning environment, hence there is a need to this research to understand a definition and find out the role of social presence in new learning environment, because social presence in blended environment is still quite unknown. Therefore, the purpose of this study was to investigate definition of social presence in blended learning environment from the instructors' viewpoint. In addition, it is also to understand the social presence role in Blended Learning environment. The research questions of this study are to define the social presence in blended learning environment and its role in blended learning environment.

\section{Background}

\subsection{Blended learning}

Since we began to research in Blended learning we found that this concept is both simple and complex. At its simplest, according to Garrison, and Kanuka, (2004) blended learning is the thoughtful integration of classroom face-to-face learning experiences with online learning experiences. There is considerable intuitive appeal to the concept of integrating the strengths of synchronous (face-to-face) and asynchronous (text-based Internet) learning activities. At the same time, there is considerable complexity in its implementation with the challenge of virtually limitless design possibilities and applicability to so many contexts (Garrison, and Kanuka, 2004).

On the other hand Blended Learning is a hybrid of traditional face-to-face and online learning so that instruction occurs both in the classroom and online, and where the online component becomes a natural extension of traditional classroom learning. Blended learning is thus a flexible approach to course design that supports the blending of different times and places for learning, offering some of the conveniences of fully online courses without the complete loss of face-to-face contact. The result is potentially a more robust educational experience than either traditional or fully online learning can offer (Colis \& Moonen, 2001).

Today with the emergence of the Blended Learning Environments, educational delivery has moved from just online instruction towards a mix of online and face-to-face approaches. Blended learning goes beyond barriers of time, location, and culture and has created many better opportunities for learners and instructors. Today, due to advantages of blended learning such as maximizes effectiveness, promote teacher-learner interaction, access online and physically feedback instantly and other advantage; many institutions and universities moved form online to blended learning programs and this is growing fast (Gómez and Igado, 2008).

For the purpose of this research, I used the term blended learning to describe the use of computer-based online course delivery with a mix of instructor-lead face-to-face practical activities.

\subsection{Social presence}

Social Presence concept has taken from research of Short, Williams, and Christie (1976) in the field of social psychology and communication. The term has been defined as the "degree of salience of the other person in the interaction and the consequent salience of the interpersonal relationships" (p.65). In the other words, social presence is the interlocutors in a communication medium perceive each other as real. Short et al (1976) claim that social presence is a quality and attribute of the communication media.

Rourke, Anderson, Garrison, and Archer (2001) defined social presence as the ability of learners to project themselves socially and affectively into a community of inquiry and a present a template for assessing social presence in computer mediated communication through content analysis of web-based conferencing transcripts.

$\mathrm{Tu}$ (2002a) mentions that social presence is a complicated construct and involves privacy, social relationships, communication styles, the nature of the task, feedback, and immediacy, among other items. He developed a 42-item questionnaire that identified social context, online communication, and interactivity as factors that comprise social presence (Tu, 2002a).

The concept of social presence was not originally designed for technology based communication. Initially it was studied for face-to-face, audio and television communication. In technology based communication research, social presence is used to understand interpersonal effects. According to Tu (2002a, \& b), social presence is a dynamic variable and its degree is based upon the user's perception as well as the characteristics of the communication medium. Some researchers have recognized the importance of social presence and they indicated Social presence is an important factor in improving instructional effectiveness. Richardson and Swan found that students reporting higher perceived social presence online also perceived that they learned more and were more satisfied with their instructors.

Studies conducted in higher education have shown that social presence has a significant impact on interaction, student persistence, satisfaction, improved learning, and motivation (Garrison \& Anderson, 2003; Gunawardena \& Zittle, 1997; Richardson \& Swan, 2003; Tu, 2002b).

Tu and Mcisaac (2002) hypothesized that social presence would increase interaction in the online classroom. The researchers used both qualitative and quantitative methods to study of social presence. Qualitative data were collected using observation, interview, and document analysis. Based on their analysis, the redefined social presence as "the 
degree of felling, perception, and reaction to another intellectual entity in the CMC environment" (Tu \& Mclsaac, 2002, p. 146). They concluded that the finding suggest that social presence positively influence the level of interaction and they suggest that this can be fostered by considering the characteristics of the learners, by choosing appropriate computer-mediated communication (CMC) media and by choosing appropriate instructional design elements.

Piciano (2002) examined performance in online environment in terms of social presence of student in that research social presence was encouraged using techniques fostering a sense of presence and sense of community. Overall, the findings suggested a strong relationship among perception of interaction, social presence, and learning. In addition, it was found that while perception of social presence did not have a significant relationship to scores on the course exam, it did have a positive, statistically significant relationship to performance on written assignment.

In other study, Rechardson \& Swan (2003) examined social presence in online environment and its relationship to students' performance and satisfaction with the instructor. Analyses of data showed a relationship between social presence, students' performance, and satisfaction with instructors. They found social presence is a predictor of students' performance.

In terms of importance and effectiveness of blended learning in academic achievements, motivations and satisfaction of students; this study will investigate the role of social presence in a new learning environment in higher education. On the other hand, the purpose of this study will be to understand the role of social presence in blended learning environment and also to present a definition of social presence in a blended learning environment.

\section{Methods and materials}

The approach to the research was qualitative method with Semi-structured interview. Qualitative research seeks to provide holistic descriptions of the field and situation studied. The focus on the entirety of the situation encourages researchers to provide rich descriptions of the situation (Creswell, 2003).Interviews conducted with four undergraduate instructors who were instructor and facilitator in blended learning course at ARAK University, Iran.

Chat interviews are carried out because the all instructors were far from researcher. Interviews are in Persian because Persian is official language in Iranian higher education institutions, also interviews in transcribed and analyzed looking for categories, themes that emerge from the categories, and finally concluded and reported.

\section{Results and discussion}

\subsection{Defining social presence in blended learning environment}

The responses gathered through semi-structured chat interviews with the participants were used to answer this research question. Whilst all participants in this study initially stated that they were aware of the concept of social presence, they all mentioned the importance of physical presence and social interaction that help to understand of social presence concept.

"I think social presence is more than physical presence; this is interaction between participants of group members + physical presence in class is social presence. Social presence is more than "being to gather" (R1)

Participants claimed to be in a place can not help to understand of social presence but that is a basic need. Also some of them gave an idea that personality and characteristics of students in blended class is important in social presence

"Social presence depends of student's background and personal characteristic of them especially in blended learning environment" (R3)

For some of participant having action and reaction in class is one of dimension of social presence in blended class. And one of participant gave a new about social presence he state:

"For me team working in blended is social Presence, this team work some times is online and some time is physically (for example football team as physically group, and computer game players as virtual group) but we need to have a same objective for controlling this activities" (R4)

One of participants of this study state a different point of view about social presence in blended learning environment he stated:

"Social presence is not only being together but that is ability of have communication each other into class and out of class also social presence is using other experience to help improve own experience" (R2)

For conclusion we can say that the definition of social presence that emerged from the data is: Social presence is an individual's ability to demonstrate his/her state of being in a virtual environment and traditional environment and so signal his/her availability for interpersonal transactions. Social presence is the means by which blended class participants communicate and interaction with other students and teachers, and indicates not only their presence in the blended environment but also their availability in controlling each other in blended class as cooperatively. 


\subsection{Social presence's role in higher education}

From the responses gathered through semi-structured chat interviews with the participants, it can be found that the answers to the above research question do indicate the role of social presence in blended learning.

All the respondents have suggested the term interaction in their responses. This seems to indicate that social presence has its role as a facilitator of an interactive platform among the performers/players and the actions that are taking place. Its role as the interactor involves several actions be it in an organization. These include in a formal setting such as in learning and training situations. It can also be in informal situations such as in games and other interactive activities. Respondents in this study also have indicated that this role played by social presence forms the support for those involved in online communication to get to know each other (Kerwald, 2008). This is observed in the following responses:

"Learning environment is small form of community. I ask them to share their emotion. I want them to come and share their experience" (R1)

"I think very simple than traditional because they aren't in class physically" (R2).

"Because we are in a new world and so many concepts have changed, yes I think there is no problem to share their information" (R4).

"I think no, because they are not physically in class. Some people don't like to share their information when they aren't together physically" (R3).

The social presence acts as another effort to encourage communication among the learners. The responses from the participant indicate that the learners are willing 'to share' information (Respondents Mohammad, Davood and Sadegh). They also showed that the role social presence may be applied depends on the preference of the learners. Kerwald (2008) stated that social presence is quite dynamic. He further reiterated that social presence according to research, have indicated that the role played by the social presence should be structured depending on situations that warrant its presence and in some situation the presence can be at its disposable.

When the participations were asked what is the importance of social presence is in blended learning environment, all of them stated that without the social presence it is difficult for student and instructors to understand concepts and interaction in the real forum, especially at the beginning of the courses. They all mentioned the importance of auditory and visual cues and especially how facial expression influenced their approach to students.

“Social presence plays an important role for students' performance, student's motivation, attitude toward best environment, not only in blended learning environment but also in the other environments such as traditional and online form " $(R 1)$

\section{"With high social presence a student can influence to his/her community" (R4)}

\section{Conclusion}

Social presence is an important part of communication, whether at the bedside, in the community or even in the classroom. Instructors manifest their presence in a number of ways: in person, by telephone, or via the Internet. Although there are limitations and constraints in projecting social presence through technology, it can be done successfully. The important challenge for scholars is to continue to find ways to enhance student learning experiences without 'being there.' With the understanding of what entails social presence and benefits it brings along, facilitators and learners can further enhance effective learning.

Result of this study indicate that social presence presents itself as a platform for communication to take place be it instructor-student and student-student. It has a place in the learning process using blended learning environment. By being aware and understand the role of social presence, teaching-learning process should be conducted with greater precision to assist both the instructor and the learners themselves. However, this study can be further researched by finding out from the learners themselves. Finally, with challenges this learning forum seems to be taking place as another complementary platform for effective learning.

This study suggests that the blended form decreases the distance also increase interaction between students and instructor. In blended learning environment students getting familiar with the other students culture, and opening a door for further interaction with domestic students in the classroom. Students would also benefit from such an interaction in terms of getting to know students and learning more about other student's cultures. Overall, this study 
confirms that the role of social presence improves the quality of Iranian students' performance.

\section{References}

Allen, I. E. \& Seaman, J. (2006). Making the grade: Online education in the United States, 2006. Needham, MA: Sloan Consortium.

Caples, R. (2006). The role of social presence in online learning communities. ProQuest Digital Dissertation, UMI Number: 3222364.

Colis, B. \& Moonen, J. (2001). Flexible Learning in a Digital World: Experiences and Expectations. Kogan-Page London.

Creswell, J. W. (2003). Research Design: Qualitative, Quantitative, and Mixed Methods Approaches, (2nd ed.). Thousand Oaks, CA: Sage.

Driscoll, M. (2002). Blended learning: Let's get beyond the hype. Learning and training innovations newsline. Retrieved 28 November 2008 from: http://www.geocities.com/calcheh88/PDF/3372680960blended_learning.pdf.

Garrison, D. \& Kanuka, H. (2004). Blended Learning: Uncovering its transformative potential in Higher education. Internet and Higher Education, 7. 95-105.

Gómez, J. \& Igado, M. (2008). Blended Learning: The Key to Success in a Training Company. International Journal of Instructional Technology and Distance Learning, 5(8).

Gunawardena, C. N. \& Zittle, F. J. (1997). Social presence as a predictor of satisfaction within a computer-mediated conferencing environment. American Journal of Distance Education, 11(3), 9-26.

Harasim, L. (1990). On-line education: perceptives on a new environment. Praeger. New York.

Kehrwald, B. (2008). Understanding social presence in text-based online learning environments. Distance Education. 29. (1). $89-106$.

Marcus, S. (2006). Measure by measure: how WBT can help create a social online presence; Campus-Wide Information Systems. 23, (2), 56-67.

Picciano, A. G. (2002). Beyond student perceptions: Issues of interaction, presence, and performance in an online course. Journal of Asynchronous Learning Networks, 6, 21-30.

Richardson, J. \& Swan, K. (2003). Examining social presence in online courses in relation to students' perceived learning and satisfaction. Journal of Asynchronous Learning Networks. 7, (1), 68-88.

Rourke, L., Anderson, T., Garrison, D. R. \& Archer, W. (2001). Assessing social presence in asynchronous text-based computer conference. Journal of Asynchronous Learning Networks, 5 (2), 1-17.

Short, J. A., Williams, E. \& Christie, B. (1976). The Social Psychology of Telecommunications. Wiley, London.

Tan, S., Yeo, A. \& Lim, W. (2005). Changing epistemology of science learning through inquiry with computer-supported collaborative learning. Journal of Computers in Mathematics and Science Teaching, 24 (4), 367-386.

$\mathrm{Tu}, \mathrm{C} . \mathrm{H}$. (2002a). The measurement of social presence in an online learning environment; International Journal on E-Learning, 1(2), 34-35.

Tu, C. H. (2002b). The impacts of text-based CMC on online social presence. The Journal of Interactive Online Learning, 1(2) 1-24.

Tu, C. H. \& McIsaac, M. S. (2002). The relationship of social presence and interaction in online classes. The American Journal of Distance Education, 16(3), 131-150.

Yildiz, S. (2009). Social Presence in the Web-Based classroom: Implications for intercultural communication. Journal of Studies in International Education. 13, 46-67. 